\title{
Quality assessment of nine paracetamol 500 mg tablet brands marketed in Saudi Arabia
}

\author{
Reem AlSwayeh ${ }^{1}$, Syed N. Alvi ${ }^{1}$ and Muhammad M. Hammami ${ }^{1,2^{*}}$ (D)
}

\begin{abstract}
Objective: To evaluate in-vitro quality of paracetamol 500 mg tablet brands marketed in Saudi Arabia.

Results: Two reference (R1 and R2) and seven generic (G1-G7) brands were commercially available. Four brands were single-drug, containing paracetamol only (R1, G1-G3) and five contained additional active ingredients (R2, G4-G7). All brands were immediate-release. Weight variation ( $n=20$, range as percent difference from mean), active substance content ( $n=20$, mean (SD) as percent difference from label), breaking force $(n=10$, mean (SD)), and friability $(n=20$, as percent weight loss) ranged from 97 to $102 \%, 96.1 \%$ (2.9\%) to $99.8 \%(1.1 \%), 9.9(0.4)$ to $21.0(0.9) \mathrm{kg}$, and $0.017 \%$ to $0.809 \%$, respectively. Disintegration (water medium) time $(n=6$, minute: second) ranged from 02:35-03:09 to 12:49-13:10. Dissolution (phosphate buffer, pH 5.8) profile showed a mean release at 30 min of $87 \%$ to $97 \%$ of label content, with seven brands passing stage- 1 ( $\geq 85 \%$ for each of 6 test units) and two passing stage-2 (mean of 12 test units $\geq 85 \%$ ) criteria. Despite statistically significant differences between R1 and R2 and some of their corresponding generic brands in active substance content, breaking force, and amount dissolved at $30 \mathrm{~min}$, all nine brands met the pre-specified quality standards.
\end{abstract}

Keywords: Paracetamol, Pharmaceutical quality, Saudi market, Dissolution profile, Generic brands, Reference brands, Combinational drugs

\section{Introduction}

The World Health Organization, among others, has continuously advocated the use of generic drug products because they expand healthcare accessibility [1]. However, lay people [2] and occasionally healthcare workers [3] not infrequently view local drug products as inferior to imported ones, questioning their quality and interchangeability.

Most countries, including Saudi Arabia, require that generic drug products pass standard in-vivo bioequivalence testing before marketing [4]. Although this should be assuring, ongoing evaluation of marketed products is critical to maintain trust. Performing such evaluation

*Correspondence: muhammad@kfshrc.edu.sa

${ }^{1}$ Clinical Studies and Empirical Ethics Department, King Faisal Specialist Hospital and Research Centre, P O Box \# 3354 (MBC 03), Riyadh 11211,

Saudi Arabia

Full list of author information is available at the end of the article in-vitro is gaining regulatory support and has the advantages of saving money and time and of not requiring involvement of human research subjects [5-8].

Paracetamol (acetaminophen) is a cheap, widely used analgesic and antipyretic drug that is available over-thecounter [9]. It is commercially available for oral intake as immediate-release tablets of various strengths, alone or in combination with other active ingredients [10].

We previously reported the pharmaceutical quality of various diclofenac tablet formulations available on the Saudi market $[11,12]$. The aim of this study was to evaluate in-vitro quality of paracetamol $500 \mathrm{mg}$ tablet brands marketed in Saudi Arabia.

\section{Main text}

\section{Drugs and chemicals}

We assessed all single-drug and combinational brands of paracetamol $500 \mathrm{mg}$ immediate-release tablet that were 
commercially available in Riyadh, Saudi Arabia at the time of the study (September to December 2020). We were able to locate two reference (R1 and R2) brands and seven generic (G1-G7) brands. R1 and G1-G3 contained only paracetamol, while R2 and G4-G7 contained other active ingredients (caffeine, codeine, pseudoephedrine, or diphenhydramine). Label information of the studied brands is presented in Additional file 1: Table S1: Label information.

We purchased paracetamol (acetaminophen) reference standard from Sigma-Aldrich CO., Louis, MO., USA; HPLC grade methanol and acetonitrile from Fisher Scientific, Fair Lawn, NJ, USA; and sodium phosphate monobasic and sodium phosphate dibasic from Fisher Chemical, Fair Lawn, New Jersey, USA. HPLC grade water was prepared by reverse osmosis and was further purified by passing through a Milli-Q System (Millipore, Bedford, MA, USA).

\section{Instruments}

High performance liquid chromatography (HPLC)-dissolution system consisted of Waters 2690D Separation Module, Hanson Research SR8-Plus, United States Pharmacopoeia (USP) dissolution apparatus II (paddle), and Waters 996 photodiode array detector (Waters Associates Inc., Milford, MA. USA). Mettler AT20 sensitive balance was purchased from Mettler Toledo (Greifensee, Switzerland). Model SSE-731 Microprocessor Disintegration Test Apparatus, Model SSE-710 Microprocessor Friability Apparatus, and Model SSE-DIGIT AB-SPV Digital Tablet Hardness Tester were purchased from Sunshine Scientific Equipment, Delhi, India.

\section{Sample preparation \& HPLC assay}

We prepared paracetamol stock solution in water and diluted it to produce standard curve samples of 40,80 , $160,240,320,480,560$, and $700 \mu \mathrm{g} / \mathrm{ml}$, and quality control samples of 40, 120, 350, and $630 \mu \mathrm{g} / \mathrm{ml}$. A previously reported HPLC assay [13] was used to determine active substance content (ASC) and dissolution profiles. The assay uses Symmetry Shield RP18, $5 \mu \mathrm{m}$ cartridge and a mobile phase composed of water, methanol, and acetonitrile $(80: 10: 10, \mathrm{v}: \mathrm{v}: \mathrm{v})$, delivered at a flow rate of $0.9 \mathrm{ml} /$ minute. The analysis was performed under isocratic condition (column and sample compartment temperature $40{ }^{\circ} \mathrm{C}$ and $8{ }^{\circ} \mathrm{C}$, respectively). The photodiode array detector was set at $245 \mathrm{~nm}$. There was no interference from tablet's excipients. We used a standard curve with eight non-zero points $(40,80,160,240,320,480,560$, $700 \mu \mathrm{g} / \mathrm{ml}$ ) and three sets of four quality control samples $(40,120,350,630 \mu \mathrm{g} / \mathrm{ml})$ in each run. Mean (SD) accuracy and coefficient of variation $(n=9)$ were $103.6 \%$ $(2.4 \%)$ and $5.3 \%(2.9 \%), 99.1 \%(5.0 \%)$ and $2.9 \%(1.8 \%)$,
99.6\% (3.9\%) and 3.5\% (2.0\%), and 102.3\% (2.7\%) and 3.0\% (2.7\%) for the four quality control samples, respectively.

\section{Quality control tests \& calculations}

For weight variation, friability, and ASC tests 20 randomly-selected units of each brand were examined. For the weight variation test, we calculated mean (SD) and percent deviation of individual unit's weight from mean weight of the brand. For the friability test, units were weighted, placed in a friabilator operated at 25 revolutions/minute for $4 \mathrm{~min}$, then weighted again after dedusting. We determined friability as percent weight loss. For the ASC test, the units were individually crushed, dissolved in $100 \mathrm{ml}$ water, filtered with a syringe using $0.2 \mu \mathrm{m}$ filter, and diluted in water, and $20 \mu \mathrm{l}$ were injected into the HPLC system. We calculated mean (SD) content and percent deviation of individual units from label.

For tablet breaking force test, 10 randomly-selected units of each brand were examined and mean (SD) pressure required to break each unit was determined.

Six randomly-selected units of each brand underwent disintegration testing. We placed the basket rack in a $1000 \mathrm{ml}$ vessel containing $900 \mathrm{ml}$ water $\left(37 \pm 2{ }^{\circ} \mathrm{C}\right)$. The basket rack moved 5-6 $\mathrm{cm}$ up and down (31 cycles/ minute) with the test unit remaining $1.5 \mathrm{~cm}$ below liquid surface and $2.5 \mathrm{~cm}$ above beaker bottom. We determined range of disintegration time (time to no particle on the basket).

Eight randomly-selected units of each brand initially underwent dissolution testing. If one or more units failed, additional 4 units were examined. $900 \pm 1 \% \mathrm{ml}$ of phosphate buffer ( $\mathrm{pH}$ 5.8) was used as dissolution medium. It was composed of $0.05 \mathrm{M}$ sodium phosphate dibasic and $0.05 \mathrm{M}$ sodium phosphate monobasic (50: $50, \mathrm{v}$ : v). Temperature was maintained at $37 \pm 0.5{ }^{\circ} \mathrm{C}$ using constant bath temperature. Stirring rate was $50 \pm 1$ rounds per minute (rpm) for $60 \mathrm{~min}$ and then the test ended with a stirring rate of $150 \mathrm{rpm}$ for $15 \mathrm{~min}$ ("infinity"). One ml sample was withdrawn midway between dissolution medium surface and rotating blade top, $\geq 1 \mathrm{~cm}$ away from vessel wall, and was immediately replaced with fresh medium. The samples were withdrawn at $5,10,15$, 20, 30, 40, 60, and $75 \mathrm{~min}$. We kept the vessels covered, verified mixture temperature, and observed unit's behavior throughout the test. We injected $20 \mu \mathrm{l}$ of the one $\mathrm{ml}$ samples into the HPLC system. We determined mean (SD) amount released and percent of label ASC released, at each time point.

We compared ASC, breaking force, and amount dissolved at $30 \mathrm{~min}$ of R1 to G1, G2, and G3 (each contains paracetamol only) and of R2 to G4, G5, G6, and G7 (each contains paracetamol plus other active substances) using 
unpaired $\mathrm{t}$ test. Two tailed $\mathrm{p}$ value $<0.05$ was considered significant.

\section{Results}

Table 1 summarizes the main results of the study. Mean weight of the nine brands ranged from 553.2 (3.3) to 838.1 (10.5) mg. Weight range was within $97-102 \%$ of mean weight for each brands. Mean (SD) ASC ranged from $96.1 \%$ (2.9\%) to $99.8 .2 \%$ (1.1\%). Both parameters were within the acceptable limits $(\leq \pm 5 \%$ and $90-110 \%$, respectively) for each brand. However, R1 ASC was significantly lower than G1 ASC $(p=0.0002)$ and G2 ASC $(\mathrm{p}=0.03)$, and R2 ASC was significantly higher than G4 $\operatorname{ASC}(\mathrm{p}=0.0001)$.

Mean (SD) breaking force ranged from 9.9 (0.4) to $21.0(0.9) \mathrm{kg}$. R1 breaking force was significantly lower than $G 2$ breaking force $(\mathrm{p}=0.0001)$ and significantly higher than $\mathrm{G} 3$ breaking force $(\mathrm{p}=0.0001)$. On the other hand, R2 breaking force was significantly higher than G4 breaking force $(\mathrm{p}=0.0001)$ and significantly lower than G5 braking force $(\mathrm{p}=0.0001)$ and $\mathrm{G} 7$ breaking force $(\mathrm{p}=0.0001)$. Weight loss due to friability ranged from $0.017 \%$ to $0.809 \%$, which is within the acceptable limit of $\leq 1 \%$.

Disintegration time was variable. It ranged from 02:35 to $03: 09$ min: second for G1 to $12: 49$ to $13: 10 \mathrm{~min}$ : second for G7. Nevertheless, all integration times were within the acceptable limit of $\leq 15 \mathrm{~min}$.

Dissolution profiles of R1, R2 and G1-G7 are shown in Fig. 1. Each of the 8 units of all brands except G4 and G7 released $\geq 85 \%(\mathrm{Q}(80 \%)+5 \%)$ of label ASC within $30 \mathrm{~min}$ and thus met the acceptance criteria of stage- 1 ( $\geq 85 \%$ release from each of 6 test units). [14] However, because 4 and 1 of the 8 units of G4 and G7, respectively, released $<85 \%$ of label ASC by $30 \mathrm{~min}(80-84 \%$ and $82 \%$, respectively), an additional 4 units were tested for each brand. Mean percent release for 12 units of G4 and G7 was $87 \%$ and $96 \%$, respectively, meeting the acceptance criteria of stage-2 (mean release of 12 test units $\geq 85 \%$ ) [14]. During dissolution, we did not observe any artifact such as coning, gumming, capping, sticking, etc. for any of the brands. Interestingly, amount dissolved at 30 min was significantly higher for R1 compared to G1 (mean (95\% confidence interval), 29.2 (23.2 to 35.2$) \mathrm{mg}$, $\mathrm{p}=0.0001$ ) and $\mathrm{G} 2$ (mean difference 10.1 (4.0 to $16.2 \mathrm{mg}$, $\mathrm{p}=0.003$ ). Amount dissolved at $30 \mathrm{~min}$ was also significantly higher for R2 compared to G4 (mean difference 40.8 (22.7 to 58.9 ) $\mathrm{mg}, \mathrm{p}=0.0002$ ).

\section{Discussion}

We assessed the pharmaceutical quality of 2 reference and seven generic paracetamol $500 \mathrm{mg}$ immediaterelease tablet brands that were commercially available on the Saudi market at the time of the study. All brands passed in-vitro quality testing according to USP [15]. Namely, weight variation of $\leq \pm 5 \%$ from mean weight (since tablet weight was $\geq 250 \mathrm{mg}$ ); mean ASC between 90-110\% of label; $\leq 1 \%$ weight loss due to friability; complete disintegration in water within $15 \mathrm{~min}$; and release of $\geq 85 \%$ within 30 min in phosphate buffer ( $\mathrm{pH} 5.8$ ).

The reported quality of paracetamol tablets on other markets is variable [16-18]. As examples, Zaid et al. evaluated the quality of 10 paracetamol products on the Palestinian market and concluded that generic products are often in-vitro comparable to the innovator product [16]. Similar conclusion was reached by Ukwueze et al. after studying six brands of paracetamol generic formulations marketed in Nigeria [17]. However, in a study from

Table 1 In-vitro quality of two reference and seven generic paracetamol $500 \mathrm{mg}$ tablet brands available on the Saudi market

\begin{tabular}{|c|c|c|c|c|c|c|c|c|}
\hline \multirow[t]{2}{*}{ Code } & \multicolumn{2}{|l|}{ Weight $n=20$} & \multicolumn{2}{|c|}{$\begin{array}{l}\text { Active substance content } \\
\mathrm{n}=\mathbf{b}\end{array}$} & \multirow{2}{*}{$\begin{array}{l}\text { Breaking force } \\
n=10 \\
\text { Mean (SD), kg }\end{array}$} & \multirow{2}{*}{$\begin{array}{l}\text { Friability } n=20 \\
\% \text { loss }\end{array}$} & \multirow{2}{*}{$\begin{array}{l}\text { Disintegration } \\
\mathrm{n}=6 \\
\text { Range minute: } \\
\text { second }\end{array}$} & \multirow{2}{*}{$\begin{array}{l}\text { Dissolution }^{\mathrm{e}} \mathrm{n}=8 \\
\text { Mean (range) } \\
\text { release at } 30 \mathrm{~min} \text {, } \\
\% \text { of label }\end{array}$} \\
\hline & Mean (SD), mg & $\begin{array}{l}\text { Range }^{a} \text {, } \\
\% \text { from } \\
\text { mean }\end{array}$ & Mean (SD), mg & $\begin{array}{l}\text { Mean (SD), } \\
\% \text { of label }\end{array}$ & & & & \\
\hline R1 & $599.6(4.1)$ & 99-101 & $480.4(14.6)$ & $96.1(2.9)$ & $15.4(0.7)$ & 0.017 & $04: 21-04: 58$ & 97 (96-98) \\
\hline G1 & $569.4(4.3)$ & 98-102 & $497.8(12.3)$ & $99.6(2.5)$ & $16.3(1.5)$ & 0.625 & 02:35-03:09 & 91 (88-93) \\
\hline G2 & $560.6(4.3)$ & 99-101 & $489.9(12.8)$ & $98.0(2.6)$ & $18.8(1.2)$ & 0.809 & 04:23-04:56 & $95(92-97)$ \\
\hline G3 & $553.2(3.3)$ & 99-101 & $485.9(4.9)$ & $97.2(1.0)$ & $13.1(0.9)$ & 0.378 & 04:42-05:35 & $97(94-100)$ \\
\hline R2 & $688.4(5.8)$ & 99-101 & $498.9(5.7)$ & $99.8(1.1)$ & $14.9(0.9)$ & 0.366 & 05:16-07:51 & 95 (94-97) \\
\hline G4 & $744.1(5.7)$ & 99-101 & $488.6(6.0)$ & $97.7(1.2)$ & $9.9(0.4)$ & 0.717 & $10.39-10.59$ & $87(80-96)^{f}$ \\
\hline G5 & $560.6(4.3)$ & 99-101 & 497.5 (4.2) & $99.5(0.8)$ & $18.3(1.7)$ & 0.351 & 8:43-9:30 & 96 (91-99) \\
\hline G6 & $797.3(4.5)$ & 99-101 & $498.0(5.4)$ & $99.6(1.1)$ & $15.3(1.5)$ & 0.526 & 9:02-10:13 & 96 (94-98) \\
\hline G7 & $838.1(10.5)$ & $97-102$ & $498.1(4.6)$ & $99.6(0.9)$ & $21.0(0.9)$ & 0.167 & 12:49-13:10 & $96(82-100)^{f}$ \\
\hline
\end{tabular}

${ }^{a}$ Acceptable variation limits, $\leq \pm 5 \%$ (for tablets $\geq 250 \mathrm{mg}$ ). ${ }^{\mathrm{b}}$ Acceptable limits, mean content $90-110 \%$ of label. ${ }^{\mathrm{c}}$ Acceptable limit, $\leq 1 \%$. ${ }^{\mathrm{d}}$ Water medium, acceptable limit, $\leq 15$ min. ${ }^{e}$ Phosphate buffer ( $\left.\mathrm{pH} 5.8\right)$ medium, acceptable limit, $\geq 80+5 \%$ of label. ${ }^{\mathrm{f}}$ Mean (range) of 12 rather than 8 units 

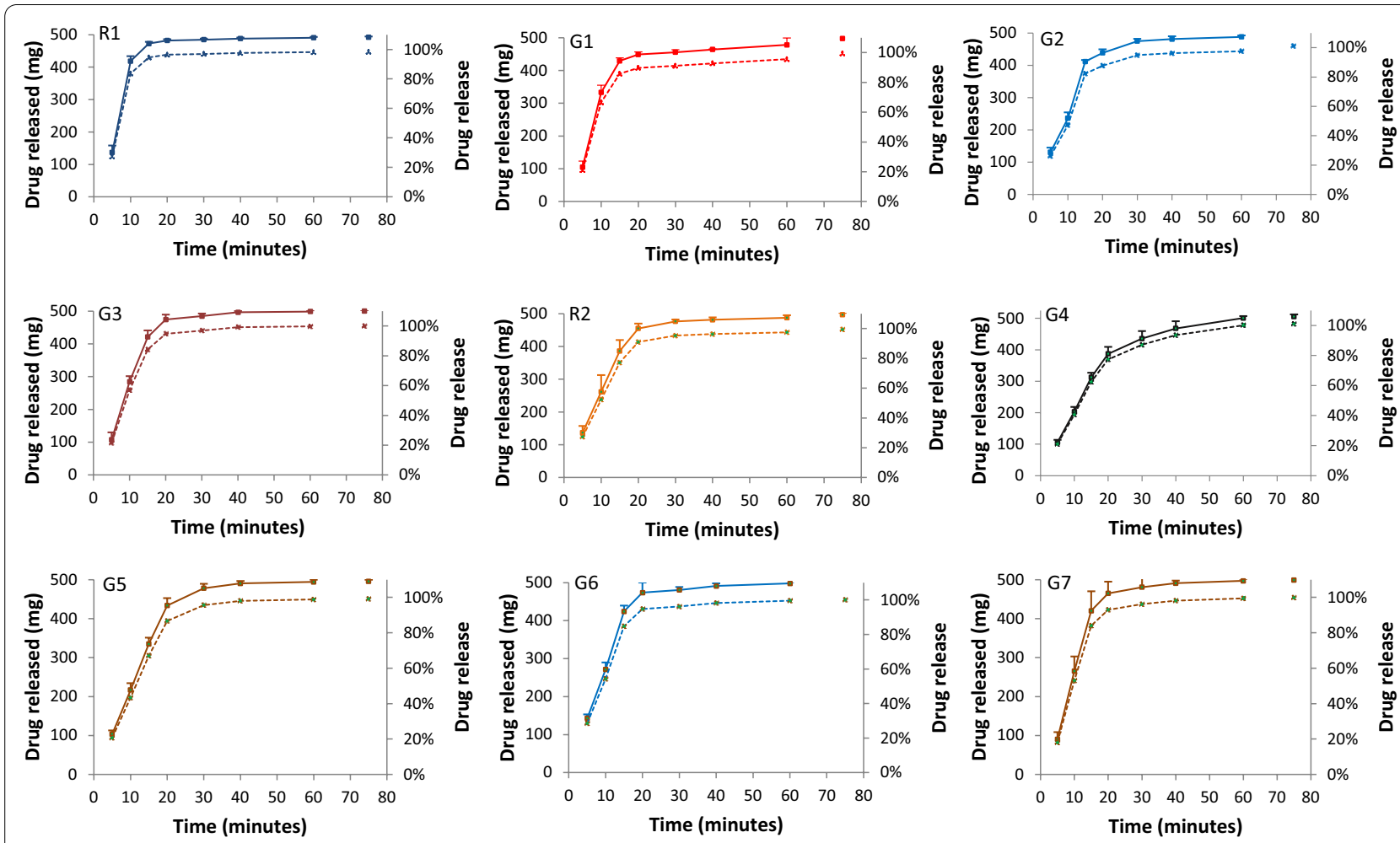

Fig. 1 Dissolution profiles of two references and seven generic paracetamol $500 \mathrm{mg}$ tablet brands available on the Saudi market. Mean (SD) amount of drug released at the specified times are shown on the left axis (continuous line) and percent of label amount released on the right axis (interrupted line). United States Pharmacopoeia (USP) dissolution apparatus type II (paddle apparatus) was used with a stirring rate of $50 \pm 1 \mathrm{rpm}$ (except for "infinity" time) and a temperature of $37 \pm 0.5^{\circ} \mathrm{C}$. Brands' label details are available in Additional file 1: Table S1. Label information. R1 and $\mathrm{R} 2$, reference brands; $\mathrm{G} 1$ to $\mathrm{G} 7$, generic brands. Dissolution medium was phosphate buffer ( $\mathrm{pH}$ 5.8). Time 75 min indicates amount released with a stirring rate of 150 rpm for 15 min ("infinity")

Malawi, out of 11 paracetamol brands, one failed ASC testing, and three failed friability testing [18].

The current results together with the results of invitro quality studies of drug products containing other active ingredients, $[11,12]$ in-vivo pre-marketing studies [19-26], and in-vivo post-marketing study [27] provide assurance of the quality of generic drug products commercially available in Saudi Arabia.

\section{Study strengths}

The study assessed all commercially available brands, included two reference brands, examined multiple-point dissolution curves, and used a validated HPLC assay.

\section{Study limitations}

Our results do not apply to other paracetamol $500 \mathrm{mg}$ tablet brands that are listed on the Saudi formulary but were not commercially available at the time of the study. Further, our results do not apply to paracetamol formulations of other strength or form. Furthermore, the specific variations in manufacturing procedures that led to the observed differences among the different brands were not addressed in this study.

\section{Abbreviations \\ ASC: Active substance content; G: Generic brand; HPLC: High performance liquid chromatography; R: Reference brand; rpm: Rounds per minute; SD: \\ Standard deviation; USP: United States Pharmacopoeia.}

\section{Supplementary Information}

The online version contains supplementary material available at https://doi. org/10.1186/s13104-021-05672-y.

Additional file 1: Table S1. Label information of two reference and seven generic paracetamol $500 \mathrm{mg}$ tablet brands available on the Saudi market.

\section{Acknowledgements}

Not applicable.

\section{Authors' contributions}

MMH designed the study, performed data analysis, and wrote the manuscript. RAS and SNA performed the experiments, co-analyzed data, and critically reviewed the manuscript. All authors agree to be accountable for all aspects of the work and approved the final version of the manuscript. All authors read and approved the final manuscript. 


\section{Funding}

Not applicable.

\section{Availability of data and materials}

Additional data are available in Additional file 1: Table S1. Label information. The datasets used and/or analyzed during the current study are available from the corresponding author on reasonable request.

\section{Declarations}

\section{Ethics approval and consent to participate}

This study was conducted after approval of the Research Advisory Council of the King Faisal Specialist Hospital and Research Center. The study did not involve human or animal subjects.

\section{Consent for publication}

Not applicable.

\section{Competing interests}

The authors declare that they have no competing interests.

\section{Author details}

${ }^{1}$ Clinical Studies and Empirical Ethics Department, King Faisal Specialist Hospital and Research Centre, P O Box \# 3354 (MBC 03), Riyadh 11211, Saudi Arabia. ${ }^{2}$ Alfaisal University College of Medicine, Riyadh, Saudi Arabia.

Received: 10 December 2020 Accepted: 24 June 2021 Published online: 30 June 2021

\section{References}

1. Anonymous (2015). Access to new medicines in Europe: technical review of policy initiatives and opportunities for collaboration and research. WHO Regional Office for Europe. https://apps.who.int/iris/handle/10665/ 159405. Accessed 12 Dec 2020.

2. Dunne SS, Dunne CP. What do people really think of generic medicines? A systematic review and critical appraisal of literature on stakeholder perceptions of generic drugs. BMC Med. 2015;13:173. https://doi.org/10. 1186/s12916-015-0415-3.

3. Toverud E-L, Hartmann K, Håkonsen H. A systematic review of physicians' and pharmacists' perspectives on generic drug use: what are the global challenges? Appl Health Econ Health Policy. 2015;13(Suppl 1):35-45. https://doi.org/10.1007/s40258-014-0145-2.

4. Saudi Food and Drug Authority. https://old.sfda.gov.sa/en/pages/default. aspx. Accessed 12 Dec 2020.

5. Anand O, Yu LX, Conner DP, Davit BM. Dissolution testing for generic drugs: an FDA perspective. AAPS J. 2011;13(3):328-35. https://doi.org/10. 1208/s12248-011-9272-y.

6. FDA Center for Drug Evaluation and Research. Guidance for the industry: dissolution testing of immediate release solid oral dosage forms. Rockville, MD, 1997. https://www.fda.gov/regulatory-information/search-fdaguidance-documents/dissolution-testing-immediate-release-solid-oraldosage-forms. Accessed 12 Dec 2020.

7. EMA Committee for Medicinal Products for Human Use (CHMP). Guideline on the investigation of bioequivalence. London, UK, 2010. https:// www.ema.europa.eu/en/documents/scientific-guideline/guideline-inves tigation-bioequivalence-rev1_en.pdf. Accessed 12 Dec 2020.

8. WHO Technical Report Series. Multisource (generic) pharmaceutical products: guidelines on registration requirements to establish interchangeability. 2006. No: 937. https://www.who.int/medicines/services/exper
tcommittees/pharmprep/QAS04_093Rev4_final.pdf. Accessed 12 Dec 2020.

9. Bertolini A, Ferrari A, Ottani A, Guerzoni S, Tacchi R, Leone S. Paracetamol: new vistas of an old drug. CNS Drug Rev. 2006;12(3-4):250-75.

10. Saudi Food \& Drug Authority. Drug list. https://www.sfda.gov.sa/en/ drugs-list. Accessed 12 Dec 2020.

11. Hammami MM, Hussein RF, AlSwayeh R, Alvi SN. Eight enteric-coated $50 \mathrm{mg}$ diclofenac sodium tablet formulations marketed in Saudi Arabia: in-vitro quality evaluation. BMC Res Notes. 2020;13:428. https://doi.org/ 10.1186/s13104-020-05270-4.

12. Hammami MM, AlSwayeh R, Hussein RF. Pharmaceutical quality of seven brands of diclofenac tablet on the Saudi market. BMC Res Notes. 2020;13:548. https://doi.org/10.1186/s13104-020-05385-8.

13. Alswayeh R, Alvi SN, Hammami MM. Rapid determination of acetaminophen levels in human plasma by high performance liquid chromatography. A J Pharmtech Res. 2016;6(3):710-9.

14. The International Pharmacopoeia, Ninth Edition (2019). https://apps.who. int/phint/en/p/docf/. Accessed 12 Dec 2020

15. Pharmacopeia online. USP32. http://www.uspbpep.com/usp32/pub/ data/v32270/usp32nf27s0_m200.html. Accessed 12 Dec 2020.

16. Zaid A, Rinno T, Jaradat N, Jodeh S, Khammash S. Interchangeability between paracetamol tablets marketed in Palastine. Is there a quality reason for a higher price? EMHJ. 2013;19(6):542-6.

17. Ukwueze SE, Uzochukwu IC, Ngonebu EJ. Comparative quality assessment and in vitro dissolution profile of some paracetamol tablet generics marketed in Nigeria. Port Harcourt Med J. 2008;3:85-90.

18. Khuluza F. In vitro evaluation of the quality of paracetamol and cotrimoxazole tablets used in Malawi based on pharmaceutical standards. Malawi Med J. 2014;26(2):38-41.

19. Lockyer M, Al-Dgither S, AlGaai E, Yusuf A, Hammami MM. Bioequivalence of two oral formulations of nizatidine capsules in healthy male volunteers. Biopharm Drug Dispos. 2005;26(3):117-20.

20. Lockyer M, Al-Dgither S, AlGaai E, Hammami MM. Bioequivalence of two oral formulations of gatifloxacin tablets in healthy male volunteers. J Appl Res. 2005;5(1):73-9.

21. AlGaai E, Lockyer M, Al-Dgither S, Hammami MM. Bioequivalence evaluation of two formulations of fluconazole $150 \mathrm{mg}$ capsules in healthy Arab men. Biopharm Drug Dispos. 2005;26(4):143-6.

22. AlGaai E, Al-Dgither S, Lockyer M, Hammami MM. Bioequivalence study of two amoxicillin formulations. Drug Research. 2006;56(1):48-55.

23. Yusuf A, Al Gaai E, Hammami MM. Bioequivalence evaluation of two rosiglitazone tablet formulations. Drug Research. 2006;56(11):740-3.

24. Hussein R, Lockyer M, Yousuf A, AlGaai E, Abdelgaleel A, Hammami MM. Bioequivalence assessment of two domperidone tablet formulations. Drug Research. 2007;57:269-73.

25. Hussein RF, Lockyer M, Hammami MM. Bioequivalence assessment of two capsule formulations of omeprazole in healthy volunteers. Drug Res. 2007;57(2):101-5.

26. AlHawari S, AlGaai E, Yousuf A, Abdelgaleel A, Hammami MM. Bioequivalence study of two metformin tablet formulations. Drug Res. 2007;57(4):192-5.

27. Hammami MM, De Padua SJS, Hussein R, Al Gaai E, Khodr NA, AlSwayeh R, Alvi SN, Binhashim N. Generic-reference and generic-generic bioequivalence of forty-two, randomly-selected, on-market generic products of fourteen immediate-release oral drugs. BMC Pharmacol Toxicol. 2017;18:78. https://doi.org/10.1186/s40360-017-0182-1.

\section{Publisher's Note}

Springer Nature remains neutral with regard to jurisdictional claims in published maps and institutional affiliations. 